\title{
“CANto y cantor Sepultará El OLVIDO" \\ La poesía de Agripina Montes \\ DEL VALLE EN EL CONTEXTO DEL SIGLO XIX COLOMBIANO*
}

\author{
"Chant and Bard Shall Fall Into \\ ObLivion" \\ Agripina Montes del Valle's Poetry in \\ Colombian i $9^{\mathrm{TH}}$ Century
}

Diana Echeverry Fernández ${ }^{1}$, Guillermo Molina Morales²

* Artículo derivado de la investigación “Seriedad,
risa y cultura popular en la poesía hispana de la
Nueva Granada", del Grupo de Literatura del
Instituto Caro y Cuervo.
Cómo citar este artículo: Echeverry,
D., Molina, G. (2020). “Canto y cantor
sepultará el olvido". La poesía de Agripina
Montes del Valle en el contexto del siglo
xix colombiano. Estudios de Literatura
Colombiana 46, pp. 17-35. DOI: https://doi.
org/10.17533/udea.elc.n46a01
1 https://orcid.org/0000-0002-1686-6621
diana.echeverry@caroycuervo.gov.co
Instituto Caro y Cuervo, Colombia
2 https://orcid.org/0000-0001-7484-3324
guillermo.molina@caroycuervo.gov.co
Universidad Santiago de Cali, Colombia

Editores: Andrés Vergara Aguirre, Christian Benavides Martínes, Vanessa Zuleta Quintero

Recibido: 10.08 .2019

Aprobado: 22.10.2019

Publicado: 27.12.2019

Copyright: $@ 2020$ Estudios de Literatura Colombiana. Este es un artículo de acceso abierto distribuido bajo los términos de la Licencia Creative Commons AtribuciónNo comercial - Compartir igual 4.0 Internacional

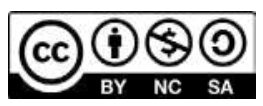

Resumen: el presente artículo recupera la figura de Agripina Montes del Valle, poeta colombiana del siglo xix, muy poco leída actualmente a pesar del reconocimiento de su época. En primer lugar, recordamos su vida y su obra, dispersa en múltiples publicaciones. Posteriormente, estudiamos su lugar como mujer en la "ciudad letrada". En el tercer apartado, nos centramos en sus poemas de contenido social y encontramos una articulación entre el deseo de progreso y la resignación religiosa. Finalmente, valoramos logros y limitaciones de sus versos, y su importancia en el contexto de la poesía colombiana.

Palabras clave: Agripina Montes del Valle; poesía colombiana; imagen de la mujer; mito del progreso.

Abstract: This paper is an attempt to retrieve the figure of Agripina Montes del Valle, a $19^{\text {th }}$ Century Colombian poet who has little recognition nowadays. Our first goal is to remember her life and work by recovering scattered poems in numerous publications. Later, we study the role of the poet as a woman in the "lettered city" of her time. In the third part, we focus on poems with social content in order to analyze her oscillatory thinking between the desire for progress and religious resignation. Finally, we consider the achievements and limitations of her verses, and its relevance in $19^{\text {th }}$ Century Colombian poetry.

Keywords: Agripina Montes del Valle; Colombian poetry; women's role; myth of progress. 
En las últimas décadas, la crítica ha intentado revalorizar el trabajo literario de las mujeres en la Colombia del siglo xix. Destaca, en este sentido, el esfuerzo realizado en torno a Soledad Acosta de Samper, quien quizás haya opacado parcialmente la existencia de un alto número de mujeres escritoras en la época, particularmente en el género de la poesía. Entre estas autoras sobresale por méritos propios la figura de Agripina Montes del Valle (1844-1915), quien solía firmar con los pseudónimos de "Porcia" y "Azucena del Valle", además de con su propio nombre. El caso de Montes del Valle es, en algunos aspectos, paradigmático de la escritura de mujeres en el siglo XIX, pero al mismo tiempo muestra diferencias que la particularizan en su contexto y que merecen una especial atención crítica.

Aunque Montes del Valle logró un gran reconocimiento en su época, no sería exagerado decir que en la actualidad su nombre yace en un olvido casi completo. A la ausencia total de monografías sobre su obra, se suman las dificultades para leer los poemas, puesto que no existe ninguna edición moderna. El único intento en este sentido fue realizado por Bedoya Martínez, pero se trata de una recopilación difícil de encontrar y, sobre todo, carente del necesario rigor académico. Así pues, el lector actual solamente puede encontrar la obra de Montes del Valle en algunas antologías, que repiten sistemáticamente las mismas piezas, en especial la oda "Al Tequendama". Algo similar sucede con las historias de la literatura colombiana: o no aparece en absoluto el nombre de Montes del Valle (es significativa su ausencia tanto en el celebrado Manual de literatura colombiana, editado por Procultura en 1988, como en la Historia de la poesía colombiana publicada por la Casa Silva) o lo hace en una brevísima mención.

Ante este sesgo, frecuente hacia las mujeres que escriben, la crítica contemporánea ha intentado una tímida recuperación de su nombre. En la mayoría de casos, se trata de menciones en estudios generales sobre escritoras que repiten los pocos datos conocidos sobre la autora y las valoraciones superficiales, basadas siempre en los mismos poemas. Así, los comentarios de Dejong (1995), Orjuela (2000), Acevedo Ramos (2016) y otras referencias todavía más minúsculas. El artículo divulgativo de Aristizábal-Montes (1999), aunque se refiere en exclusiva a la poeta, no escapa de los tópicos sobre la escritura femenina. Urge, por lo tanto, una investigación como la que ahora presentamos, la primera dedicada a profundizar en la obra de Agripina Montes del Valle. 
Al tratarse de una autora prácticamente desconocida, comenzaremos con un breve perfil intelectual, para lo que nos remontaremos a las publicaciones del siglo XIx. Después, estudiaremos el lugar de la poeta Montes del Valle en la "ciudad letrada" de su tiempo, así como el contraste entre su obra y las creencias de la época sobre el papel de las mujeres en la cultura. En el tercer apartado, nos centraremos en las piezas de contenido sociopolítico, por ser las más relevantes desde nuestro juicio crítico, y estudiaremos la visión que proponen estos poemas sobre los problemas sociales de su tiempo. Con todos estos elementos, podremos extraer conclusiones sobre la importancia de nuestra autora para la poesía decimonónica de Colombia.

\section{Vida y obra de Agripina Montes del Valle: reconocimiento y olvido}

Tal y como habíamos avanzado en la introducción, el caso de Agripina Montes del Valle resulta, en varios aspectos, peculiar para su tiempo. La primera de estas particularidades es su origen social. Nació en 1844 en el pueblo de Salamina (entonces parte de Antioquia, hoy de Caldas), un enclave importante en la ruta de la colonización antioqueña. Si bien la familia Montes del Valle tenía acceso a la cultura escrita (hubo periodistas y políticos entre sus miembros), se situaba en lo que hoy llamaríamos "clase media" provinciana. Así pues, Agripina tuvo que luchar para encontrar un espacio en la élite letrada de Santafé de Bogotá, a donde llegó para seguir sus estudios, en el Colegio de la Merced, cuando tan solo contaba con diez años de edad. La joven Montes del Valle logró un temprano éxito en la capital, si tenemos en cuenta que en 1864 ya publicaba poemas en El Mosaico, la revista literaria dirigida por el "patriarca" de las letras locales, José María Vergara y Vergara. Aquí, Montes del Valle coincidió

con otras mujeres poetas, como Agripina Samper de Ancízar y Silveria Espinosa de Rendón, que contaban con el "aval" de ser hijas, hermanas o esposas de intelectuales prestigiosos en Santafé. En este sentido, Montes del Valle fue una de las pocas mujeres que logró desarrollar una carrera como escritora sin apoyo masculino previo.

Es más, el matrimonio que efectuó en 1865 con Miguel María del Valle Lince, en la ciudad de Manizales, supuso un obstáculo para continuar su vocación literaria. Lo afirma ella misma tres años después en un artículo titulado "Proyectos de literatura", al que nos referiremos más tarde. A pesar de ello, Montes del Valle continuó publicando, principalmente poemas, en varias revistas literarias de su tiempo, como La mujer, El 
Mosaico, El Iris y El Nuevo Tiempo Literario. Además, Montes del Valle emprendió una importante labor como educadora: en 1870 funda en Manizales (ciudad en la que vivía tras su matrimonio) el Colegio de la Concepción. Sabemos que también ejerció como profesora en Bogotá y que, posteriormente, llegaría a ser directora de la Escuela Normal del Magdalena, en 1877.

Montes del Valle consolidó definitivamente su trayectoria literaria en la década larga transcurrida entre los años 1872 y 1883. En la primera de estas fechas, la poeta obtiene una medalla de honor en un certamen poético celebrado en Santiago de Chile, por su poema "A la América del Sur". Posteriormente, triunfa en un certamen convocado en la capital de su país por su "Canto al trabajo", en el año 1881. Un poco después, en 1883, Montes del Valle fue la única mujer, entre los 37 poetas invitados, que incluye un poema (el romance histórico "Policarpa Salavarrieta") en Romancero colombiano: homenaje de Colombia al Libertador Simón Bolivar en su primer centenario. La recopilación, por su temática nacionalista, supone un escaparate de mucha relevancia para la ciudad letrada de la época.

Si bien Montes del Valle logra reconocimiento por las citadas obras, de temática histórica y sociopolítica, son muy distintos los poemas de circunstancias, dedicados a familiares y personalidades letradas, que paralelamente publica en revistas y periódicos. Sin embargo, las alabanzas allí contenidas le ayudaron a ganarse el favor del medio literario. Destacan, en este sentido, los poemas dedicados a mujeres que formaban parte de la élite, como Agripina Samper de Ancízar. Además de celebrar o lamentar hechos puntuales (cumpleaños, funerales, peticiones de amigos, álbumes de señoritas, etc.), estos poemas muestran un tono sentimental y lacrimógeno, esperable en una mujer "sensible" en la época del Romanticismo. ${ }^{1}$

1 La lista completa de los poemas que hemos encontrado publicados por Montes del Valle en revistas y periódicos anteriores a 1883 es la siguiente: en El Mosaico, "A mi amiga. La sensible poetisa Leonor Blander" y "Recuerdos de una tarde" (1864), "Los últimos instantes de Magdalena, La hija extraviada" (1871), "Silva a la muerte. Exigencia de un amigo", "Silva. En la muerte de mi hijo. A mi querida hermana la señorita Vicenta del Valle", "La ausencia. A mi querido esposo" y "Jose Maria Vergara y Vergara” (1872). En El Iris aparecen las piezas “Adios!”, "El ave del proscrito” (1866), “A Jorje Isaacs” (1867) y "Un recuerdo a la señorita M.M. Imitación de Byron" (1868). Para El Hogar publicó “A mi querida amiga Clotilde Tirado de García” (1869). En La Mujer aparecen las composiciones "Dios. A mi señora doña Pia A. de B.”, "A mi señora doña Carmén de Várgas, en su día”, "Tus ojos. Á la señorita Angelina Aguiar Toscano", "La vida de las rosas. A la señorita Rosa Várgas, en el día de su santo”(1878), “Charada”(febrero), “Charada”(marzo), “Charada”(abril), “La vida!”, "Apólogo”,"La azuzena y la rosa” publicados bajo el seudónimo Azucena del Valle, “A la señorita Rosa Franco Acosta.”, y "Un recuerdo de cariñosa amistad. En la muerte de su querida madre la señora doña Emilia Otálora de M.”(1879). 
Algunos de estos poemas ("Dios. A mi señora doña Pía A. de B.”, “Tus ojos. A la señorita Angelina Aguiar Toscano" y "La vida de las rosas. A la señorita Rosa Vargas") fueron incluidos en el libro de Poesías que la propia Montes del Valle recopiló en 1883. La mayoría de los poemas del libro, sin embargo, eran inéditos en aquel momento, y muestran una particular inclinación hacia la temática sociopolítica, que analizaremos en el apartado tercero del presente artículo. El volumen publicado dice ser el primero de una serie, pero sería el único en salir a la luz, posiblemente por razones económicas. De hecho, hemos encontrado un documento que hasta ahora no había sido mencionado en los estudios sobre la autora: la Ley 62 del 7 de septiembre de 1882, en que el gobierno de los Estados Unidos de Colombia (presidido por Francisco Javier Zaldúa con el consenso de liberales y conservadores) concede quinientos pesos a la poeta para publicar sus obras. De este documento puede inferirse que Montes del Valle, a los 38 años de edad, gozaba de un prestigio completamente consolidado. Dicho prestigio se reafirmó gracias al prólogo a las Poesías, firmado por Rafael Pombo, el poeta más reconocido del siglo XIX.

En 1887, el mismo año en que se queda viuda, su fama aumentó por la publicación de la oda "Al Tequendama” en la antología El Parnaso colombiano, compilada por Julio Añez. A partir de ese momento, su nombre quedó asociado al del famoso salto, hasta el punto de que se la conocía con el sobrenombre de “La Musa del Tequendama”. Poco después, en 1888, este mismo poema aparece destacado en las Cartas americanas del crítico español Juan Valera (1958): "Yo no aclamo, me limito a repetir el grito de admiración con que en su patria saludan a doña Agripina” (p. 278). La fama internacional de Montes del Valle queda comprobada con la mención de su nombre que realiza la peruana Clorinda Matto de Turner en 1895 en su discurso "Las obreras del pensamiento en la América del Sur”. En este mismo año, otra mujer, en este caso colombiana, la cita con aplauso: se trata de Soledad Acosta de Samper en La mujer en la sociedad moderna.

La producción poética posterior a las Poesías 1883 y a la oda "AlTequendama” de 1886 es más intermitente, al menos si lo juzgamos por las publicaciones encontradas. En la mayor parte de las piezas, Montes del Valle da continuidad a una poesía de 
circunstancias que hoy nos parece de escaso interés. ${ }^{2}$ Los poemas que escapan a esta tendencia, como "Eterno amor" (1894) y “A orillas del Mar Caribe" (1908) resultan un tanto anacrónicos, si tenemos en cuenta el cambio de gusto que estaba iniciando el modernismo. Como la propia Montes del Valle expresaba, su gran proyecto de esta época fue "El último pijao. Poema en cuatro cantos", del que solamente llegó a publicar la introducción, de tono elevado cercano a la épica y descripción de una naturaleza avasalladora. De hecho, se establece una analogía entre el paisaje desértico de una tierra arrasada por la lava y el desierto humano que siguió a la Conquista de los españoles, quienes acabaron con "el último pijao" (en realidad, el pueblo pijao seguía existiendo en la época de Montes del Valle, pero era común la mitificación del indígena precolombino y el olvido o desprecio al indígena contemporáneo).

Dos datos indican que el reconocimiento hacia Montes del Valle continuó hasta su muerte, acaecida en Anolaima (Cundinamarca) en 1915. El primero, la invitación a participar en la Revista Gris. En el número dos de dicha revista (año 1892), la primera página está dedicada a nuestra poeta, a quien siguen textos de un jovencísimo José Asunción Silva y de los veinteañeros Max Grillo e Ismael Enrique Arciniegas. Este número supone una transición entre la poesía decimonónica ya consolidada, representada por Montes del Valle, y la poesía modernista que comenzaba a germinar. El papel de nuestra poeta se limita a reivindicar su propio nombre en busca de gloria y de remuneración económica: "Deseo ardientemente que la ingrata labor emprendida por ustedes deshaga el hielo del egoísmo tornándolo en buenos cuartos, que alguna remuneración ha de tener el trabajo intelectual” (Montes del Valle, 1892, p. 35). Esta afirmación puede entenderse como un intento de democratización de la cultura, ya que la profesionalización remunerada del escritor posibilitaría una mayor amplitud de orígenes sociales en la oligárquica ciudad letrada de entonces. El segundo de los hechos que nos hace pensar en la persistencia del reconocimiento hacia la autora es

2 La lista completa de los poemas que hemos encontrado publicados por Montes en revistas y periódicos posteriores a 1886 es la siguiente: figuran en Revista Gris las composiciones "El último pijao. Poema en cuatro cantos. (introducción)" " “Eterno amor" (1894). En El Nuevo Tiempo Literario presentó "A la poetisa y pintora señora doña Waldina Dávila de Ponce de León”(1905), “Elegía. A la memoria de la noblísima matrona señora doña Guadalupe Enciso de Gálvez” (1907), "A orillas del Mar Caribe”, "Elegía. A la querida memoria de la noblísima matrona señora doña Serafina Calle de Isaza”(1908), "María Lucrecia Trujillo" (1909), "Al laureado bardo y noble educacionista doctor Ruberto S. Gómez. Para sus hijos”, “A la señorita Soledad Ramos y P. en prueba de mi profundo cariño" (1911), "Elegía. A la señorita Leonor Castro Angarita en su muerte”, "A la señora doña Carmen Hernández de Arteaga. En su tumba” (1912). 
el protagonismo de Montes del Valle, en 1910, durante el acto de inauguración de la estatua dedicada a Policarpa Salavarrieta (que todavía hoy se encuentra en el entorno de Las Aguas, Bogotá).

Después de la muerte de Montes del Valle, en la primera mitad del siglo xx, su nombre todavía era recordado. E1 más reconocido crítico de estos años, Antonio Gómez Restrepo (1952), llega a afirmar que Montes del Valle es "la más ilustre de las poetisas colombianas" (p. 128), un juicio que será muy reproducido en adelante. Aunque se trate de una evaluación positiva, la clasificación entre las "poetisas" la relega a una categoría inferior, como una más en el coro de sensibles damas ornamentales. De hecho, las valoraciones sobre su obra serán cada vez menos frecuentes y más vacías y mecánicas (por ejemplo, en Ortega Torres, 1934; y en Arango Ferrer, 1965), hasta sumirse en el olvido en que actualmente encontramos a la autora.

Resulta importante resaltar que Agripina Montes del Valle, cuyo indudable prestigio en vida acabamos de recordar en estas primeras páginas (publicaciones en libro, antologías y revistas importantes; premios en certámenes literarios; juicios positivos de poetas y críticos nacionales y extranjeros, etc.), no llegó a formar parte del canon de la poesía colombiana del siglo XIx. En cambio, poetas hombres de similar o inferior mérito, como José Fernández Madrid, José Joaquín Ortiz, Diego Fallón, Epifanio Mejía o Rafael Núñez, ocupan lugares representativos en el canon de la poesía nacional, y a ellos se han dedicado un número muy superior de páginas críticas. Es difícil pensar que el motivo de la marginación de la obra de Montes del Valle sea otro que su condición de mujer, puesto que sus características y calidades estéticas se asemejan a los de sus pares masculinos. El presente artículo busca equilibrar en alguna medida esta injusta situación.

\section{Mujer y escritura en el siglo XIX: Montes del Valle en la ciudad letrada}

En el siglo xix, las élites criollas reafirmaron el imaginario sobre la mujer impuesto desde la Colonia. Las mujeres debían seguir los rasgos atribuidos a la Virgen María y limitarse siempre al ámbito doméstico. Se ensalzaban "virtudes" femeninas como la maternidad, la abnegación, la obediencia, la prudencia y el afecto; mientras que se atribuían a la condición de la mujer, como principales defectos, la inconsistencia, el sentimentalismo y la irracionalidad, por lo que no eran aptas para la participación 
política y debían permanecer subordinadas a un hombre: primero, al padre; luego, al esposo, y, al quedar viudas, a la memoria del esposo (Bermúdez,1993). Estos principios eran difundidos a través de discursos, sermones, leyes, poemas, pinturas y otros signos exteriores. Por ejemplo, el ya citado "patriarca" de la literatura colombiana, Vergara y Vergara, establecía en sus escritos cómo debía ser el comportamiento de una mujer (Alzate, 2004, pp. 273-275). Por supuesto, la transmisión de ideales comenzaba en la infancia: el capitalino Colegio de la Merced para señoritas, donde estudió Montes del Valle, fue fundado en 1830 bajo estos principios (Lux, 2015, pp. 229-230).

La literatura era una herramienta importante para la difusión de estas ideas, especialmente en un siglo dedicado a la construcción de imaginarios nacionales. La circulación de revistas y periódicos resultaba fundamental en la época. En su origen, a finales del siglo Xviı, un periódico era habitualmente escrito por una sola persona, que contaba con algún tipo de apoyo oficial (pensemos, por ejemplo, en el "padre" del periodismo colombiano, Manuel del Socorro Rodríguez). Sin embargo, en el siglo XIX, la ciudad letrada amplió el número de sus integrantes y estos, a su vez, mostraron un mayor interés en escribir para publicaciones efímeras. Esta ampliación permitió el ingreso de algunas mujeres, aunque casi siempre ligadas a una figura familiar masculina: la propia Montes del Valle (1872) señalaría su excepcionalidad al apelar a su origen social no privilegiado (p. 212).

Sin embargo, un sector de la sociedad se resistió a otorgar protagonismo al "bello sexo", pues en esta dinámica se jugaba no solo la posibilidad de que las mujeres fueran literatas, sino también que se convirtieran en figuras públicas y políticas. Las escritoras defendieron su lugar individual y colectivamente, a menudo mediante redes intelectuales femeninas. Montes del Valle actuó de la misma manera: por ejemplo, en el preámbulo a su libro mostró una fuerte defensa de su derecho a escribir. Con todo, no cabe duda de que la figura masculina de Rafael Pombo, quien escribió el prólogo, fue fundamental para la justificación de esta poesía escrita por una mujer. La estrategia tenía precedentes: en 1869, el primer libro de Soledad Acosta fue prologado por su esposo, José María Samper, quien anticipó la respuesta de los que juzgarían negativamente la publicación (Alzate, 2004, p. 276-277).

Ahora bien, aun aceptando la posibilidad de que las mujeres escribieran, los ideólogos de la época solían arrinconar su escritura al vincularla con 
las limitaciones imaginadas para las féminas. El propio Pombo (1883), en el mencionado prólogo, se refiere a la mujer como "complemento providencial del hombre" (p. XIII). En este sentido, la escritura femenina tendría como objetivo el sentimentalismo y la delicadeza, en un tono menor, sensible e íntimo. Aunque la mujer se mostraba apta para "la elevación moral y espiritual del género humano" (p. XII), como guardiana de la religión y de las buenas costumbres, su labor debía limitarse a la esfera doméstica. En su conclusión sobre estas “sacerdotisas”, Pombo recomienda que la escritora "se esfuerce (siempre que quiera ser mujer y no hombre), en ser lo más mujer y lo menos literato posible" (p. XXXIV), con lo que sigue la tradición satírica contra las "bachilleras" (el ya citado Vergara y Vergara llegaba a recomendar que si una mujer tenía talento, era su obligación ocultarlo).

Algunos poemas de Montes del Valle, en efecto, siguieron las convenciones expuestas para la escritura de mujer. Lo vemos en piezas como "La Azucena y la Rosa”, publicado en La Mujer, donde recrea un diálogo sobre el amor bajo los preceptos de la represión religiosa: "Que para vivir contenta, / Debes tener siempre exenta / Tu alma vírgen de pasion” (Montes del Valle, 1879, p. 159). Por señalar un ejemplo del libro, en "Una azucena. A la señorita Julia Lozada" relaciona la flor con la mujer bajo el símbolo de la pureza y la castidad: "de la pureza hermana / Como tu dueña hermosa, gentil y virginal” (Montes del Valle, 1883, p. 63). En estas composiciones se reproduce la imagen conservadora de la mujer, al mismo tiempo que la propia poeta se cuida de no transgredir esos límites en su trabajo poético.

Sin embargo, otras piezas de Montes del Valle muestran tensiones dentro de este imaginario. Resulta especialmente significativo el texto "Proyectos de literatura" (1868), en el que la poeta, de 24 años y ya con tres hijos, denuncia la imposibilidad de dedicar más tiempo a la literatura por un exceso de obligaciones domésticas. El escrito muestra esta problemática, de forma muy vívida, al describir una serie de escenas en que la poeta intenta encontrar un tiempo para escribir (por la noche y por el día), pero siempre es interrumpida por los hijos, el esposo e incluso las visitas, al punto de afirmar: "las mujeres casadas no seremos nunca literatas" (Montes del Valle, 1868, p. 312), ya que se sacrifican para que el marido sí pueda disponer de esta posibilidad. Es difícil no pensar en la famosa proclama de Virginia Woolf en Un cuarto propio (1929), aunque también pueden citarse otras denuncias similares en la 
propia Colombia decimonónica: por ejemplo, en 1866, una mujer anónima publicó en El Iris "De la madre de familia", texto que incluye una reivindicación similar a la de Montes del Valle; mientras que Silveria Espinosa de Rendón, en el poema "Des bas et des vers", ridiculizó a los hombres temerosos de que a una mujer que escribía pudiera faltarle tiempo para realizar labores domésticas.

En este contexto, resultaba lógico que las mujeres intentaran agruparse en redes intelectuales que les proporcionaran un mutuo apoyo. En el caso de Montes del Valle, sabemos que recibió ayuda de mujeres letradas desde el inicio de su trayectoria literaria. Ya en 1864, Agripina Samper de Ancízar presenta a Montes del Valle como su nueva amiga en un poema publicado en El Mosaico, revista donde aparecerían poemas de Montes del Valle unos meses después; de forma similar, Soledad Acosta de Samper la invitó a publicar en la revista que ella misma dirigía. Estas redes no solo servían de apoyo en una ciudad letrada predominantemente masculina, sino que también generaban espacios para discusiones de enjundia entre las propias mujeres. Así, el debate público que sostuvieron, en los años 1871 y 1872, las dos Agripinas, Montes del Valle y Samper de Ancízar, sobre cuestiones lingüísticas (por ejemplo, el uso de las grafías "y" o "i" para la conjunción copulativa), en un tiempo en que la gramática era cuestión de Estado y terreno de luchas políticas. Aunque Montes del Valle se ubica dentro de la perspectiva normativa peninsular, llama la atención el tono coloquial y el lenguaje "inapropiado" que utiliza en su argumentación (expresiones como "tontos", “saltimbanquis" y "marrano con mucha plata”), además de sus posicionamientos políticos que hoy podríamos relacionar con un impulso democrático (desconocimiento de la aristocracia, invocación de la igualdad y la aproximación de las clases sociales, lucha para la extensión de la cultura y del progreso material, etc.).

Encontramos un tono reivindicativo similar en el "Preámbulo" del libro de Poesías ya mencionado. Advierte a sus posibles críticos: "no pidais explicación al desconcierto del metro [...]. Yo he cantado por una fuerza extraña que me impele" (Montes del Valle, 1883, p. 2), escudada en el mito romántico del poeta arrebatado que supera las normas métricas. También problematiza la idea de que sus composiciones debían estar referidas exclusivamente a cuestiones íntimas: "solo sé que traje la misión de sentir y que al sentimiento que Dios puso en mi alma, le agregó la libertad de la expansión” (p. 2). Una expansión que la llevaría a tratar problemas sociales que superaban, con mucho, 
el ámbito doméstico. Interpretamos que en este breve texto Montes del Valle utiliza estratégicamente algunos mitos románticos para ampliar su espacio como mujer poeta.

Así, composiciones como "Sobre el cráter del Ruiz" o la famosa oda "Al Tequendama” están atravesadas por un sentimiento salvaje y furioso. La propia tendencia épica de sus versos supone una muestra de orgullo, casi whitmaniana, que contradice la delicadeza y mesura deseables en una mujer de su tiempo. No extraña que su poesía fuera a menudo calificada como "viril" y "poco femenina" (Ortega, 1934, p.164). Sin salir de los poemas dedicados a la naturaleza, hay otro detalle de importancia que muestran la originalidad de Montes del Valle y su intento de insertarse en la esfera de debate público. Nuestra poeta, en odas como la dedicada al río Magdalena, no se limita a la contemplación paisajística (como lo haría, por ejemplo, Waldina Dávila de Ponce, con tono nostálgico), sino que introduce un lamento sobre las guerras civiles: - "Ah! porque ley oscura / la muerte en tus orillas se pasea", y una alabanza al progreso: "Y te cruzan de naves, / Y de eléctricas vías" (Montes del Valle, 1883, pp. 95, 97). Unos versos que, por cierto, recuerdan la original “Oda al Paraná” del argentino Manuel José de Lavardén.

Incluso sin tener en cuenta los textos en prosa en los que Montes del Valle cuestiona explícitamente el imaginario sobre la mujer (en especial, "Proyectos de literatura”), las Poesias muestran una clara superación del rol tradicional asignado a la mujer poeta. Los versos ya no son usados solamente como ornamento o desahogo sentimental, sino que buscan una intervención concreta en la esfera pública. A continuación, analizaremos las ideas sociales que estos poemas contienen.

\section{E1 Romanticismo social de Montes del Valle: entre Edison y Dios}

Todo lo que conocemos de Montes del Valle, en su vida y en su obra, apunta a una personalidad fuerte que siempre buscaba nuevas formas de expansión. Esta tendencia se muestra de forma más marcada en su libro de Poesías, en donde sobresalen los temas sociopolíticos, aunque persisten algunos poemas con los lineamientos anteriores. En este sentido, resultan significativos los tres poemas que abren el libro dedicados, respectivamente, "A Dios", "A mi madre" y "A mi esposo", como una suerte de triada protectora. Existe aquí una marca de género, puesto que los hombres, por lo general, 
no escribían poemas a sus padres o esposas, y menos todavía concedían a estas piezas “domésticas” un papel protagónico.

Sin embargo, el cuarto poema, "A Mr. F. de Lesseps. El gran obrero de la civilización", supone la entrada de un tono y una temática extremadamente distintas. Recordemos que Ferdinand de Lesseps era un ingeniero de ideas progresistas, famoso por la participación en el Canal de Suez y por los proyectos para el futuro Canal de Panamá (que era entonces parte de Colombia). Su fama fue muy celebrada en América, como muestra el hecho de que, unos pocos años después (1886), el peruano Pedro Paz Soldán y Unanúe le dedicara un “Canto a Lesseps" que el propio poeta tradujo al francés. En alusión al proyecto para el Canal de Panamá (en el que finalmente fracasaría Lesseps), Montes del Valle (1883) imagina una América que, "en sus vastas soledades”, "Aguarda que en sus vírgenes entrañas / Sople tu ingenio grande y poderoso" (p. 12). Como agradecimiento al "progreso indefinido", Montes del Valle aventura que "un altar le alzará la Patria mía” (p. 13). Como vemos, el poema puede ubicarse dentro del Romanticismo social que canta a los grandes retos de la visión progresista decimonónica. Esta tendencia será constante en las Poesías de Montes del Valle, en piezas de títulos tan elocuentes como "Al progreso" y "Al trabajo".

Esbozaremos un esquema con los principales elementos de esta visión sociopolítica. En primer lugar, existe un contraste entre la realidad y el deseo, es decir, entre la concepción de América que Montes del Valle expresa en sus poemas (una América vacía y virgen) y el deseo de que esa América experimente un progreso técnico indefinido que la asimile a los modelos europeo y norteamericano. Además, Montes del Valle se ocupa de los excluidos en el proceso civilizatorio, es decir, de los pobres, para los cuales propone dos soluciones: la caridad y la resignación. Finalmente, sobresalen las referencias a los dos medios principales que guiarán el cambio: por un lado, la inspiración divina, con un Dios trabajador que puso la semilla del progreso; por otro lado, el trabajo humano, que incluye el esfuerzo físico y, sobre todo, el intelectual. Como veremos, toda esta ideología de Montes del Valle se articula en torno a dos extremos, que ella concibe como complementarios: la idea de progreso técnico y la religiosidad conservadora.

En cuanto al primer eje de análisis (de la América virginal al progreso eurocéntrico), en el ya referido "A Mr. F. de Lesseps" se explicita la idea de una América vacía que espera ansiosa la llegada del poderoso europeo. Montes del Valle 
asigna a nuestro continente un papel tradicionalmente femenino y, en consecuencia para la ideología de la época, pasivo. En cierto sentido, la poesía de Montes del Valle puede inscribirse en la línea de las muy influyentes silvas americanas de Andrés Bello. De hecho, la poeta escribe una pieza "En el centenario de Andrés Bello", en donde destaca la percepción del "virgen” espacio nativo, la oposición al "vicio enervador de la pereza", y la celebración del trabajo y "los fastos de la ciencia”, para rematar con la curiosa expresión "progreso indo-latino", altamente contradictoria con el desprecio hacia el mundo indígena. Lo cierto es que la lectura que Montes del Valle hace de Bello se diferencia bastante de las ideas expresadas por el poeta venezolano. Si bien ambos comparten la idea de una América virgen, Bello hace énfasis en la apacible naturaleza americana y en el cultivo agrícola (al igual que lo haría, por ejemplo, Gregorio Gutiérrez González, el poeta antioqueño contemporáneo de Montes del Valle), mientras que la poeta prefiere la naturaleza indómita (las cascadas del Tequendama, el Nevado del Ruiz, etc.) y el progreso técnico, ya muy lejos del idilio virgiliano.

Podríamos decir que Montes del Valle propone una segunda Conquista europea, en la línea de otros pensadores de la época. Como señala Jaramillo Uribe (1964), en la segunda mitad del siglo XIX, "los colombianos más conspicuos de las clases dirigentes miraban hacia el mundo anglosajón o hacia el francés, admirando en este sus formas políticas y en aquel su eficiencia técnica, su actitud ante el trabajo” (p. 39). Si bien es cierto que la Independencia había supuesto una crítica al "yugo español”, el imaginario colombiano del siglo xIX, por lo general, supone un simple reemplazo del colono español por el colono francés o estadounidense. Es significativo el caso de José Joaquín Ortiz, poeta conocido por las odas a la nueva nación, pero también por la alabanza a "Los colonos" españoles, que trajeron la "civilización” a América (incluso las flores, según el poema, fueron traídas por una sensible mujer española).

La idea clave que sostiene el pensamiento de Montes del Valle (1883) es el "progreso indefinido" o, como lo diríamos actualmente, el mito del progreso. Esta idea es explícita, desde luego, en "Al progreso", en que "Dios, tu rey, de quien eres vivo agente / Envió al hombre, ingeniosa maravilla" (p. 115) para que interrogue sus misterios. En esta labor, la poeta destaca, entre otros, a Thomas Alva Edison, quien ya era conocido por sus inventos, en especial el de la luz eléctrica. Edison publicita 
la primera lámpara incandescente en 1878, muy pocos años antes del poema, lo que muestra el entusiasmo que Montes del Valle mantenía por las novedades. Destaca el hecho de que la poeta enlace a Edison y a Dios, e incluso a Sócrates y Pitágoras, en un intento de crear una línea recta y coherente desde el Génesis a la locomotora.

En otro de sus poemas, "La imprenta", que dedica a Enrique Zalamea, editor del libro de Montes del Valle, la poeta relaciona, de nuevo, esta invención con el Génesis bíblico, a través de la luz: "Surgió de Guttenberg la ignota idea [...] / Y fué la luz del venturoso día / En que tomó el espíritu por guía / Del tipo la palanca gigantea" (Montes del Valle, 1883, p. 153). Esta celebración puede relacionarse con un escrito en prosa de la propia poeta, en que se refiere a la imprenta en los siguientes términos: "en el siglo de las luces cuando todo se agita, cruje, resuena, hace furor bajo el influjo irresistible de la imprenta; si lo que se siente no se pone al amparo de sus tipos corre el riesgo de que el olvido lo archive en su fosa sin salida" (Montes del Valle, 1872, p. 272). Precisamente en el llamado “siglo de las luces”, el poeta Manuel del Socorro Rodríguez, afincado en la Santafé de Bogotá todavía colonial, escribió similares poemas en alabanza a la imprenta. Encontramos aquí, por lo tanto, una continuidad en el imaginario del progreso técnico desde finales del siglo Xviı.

Ahora bien, aunque la mayoría de intelectuales de la segunda mitad del siglo XIX comentaran con admiración la idea del progreso, fueron pocos los poetas que la incorporaron en sus poemas. La vinculación de la poesía con la espiritualidad lo impedía. La única excepción fueron los autores que se habían comprometido con las políticas liberales, como Antonio José Restrepo, José María Rojas Garrido y Diógenes Arrieta. Este último poeta llegó a afirmar que la poesía solo debía ocuparse del "avance maravilloso de las ciencias, las conquistas de la libertad, el progreso que va alcanzando a todas las cimas del antiguo orden social” (en Arango Ferrer, 1965, p. 282), lo que, por cierto, resultó desastroso para la poesía de estos mismos autores. En este contexto, el caso de Montes del Valle es absolutamente excepcional, puesto que, al igual que los políticos liberales, dedica sus versos al progreso técnico; pero, a diferencia de ellos, mantiene continuamente una ideología conservadora basada en la religión.

Esta ideología se puede observar si analizamos los poemas dedicados a las diferencias sociales. En el poema "La miseria”, por ejemplo, Montes del Valle (1883) lamenta que exista este "drama sin nombre en que el delito expía” (p. 52), pero el 
principal problema de la pobreza parece ser la posibilidad de dudar del orden social, de origen divino: "Y ¡ay del triste que te halla en su camino / Si ya le asedia la maldita duda, / y te contempla lívida y desnuda, / Del mismo Dios dejada al parecer!" (p. 53). La miseria no es vista como consecuencia del injusto reparto de la riqueza, sino como una suerte de prueba divina. La solución, por lo tanto, no puede ser otra que la "Resignación" (en el libro se recoge un poema con este título) y el leve alivio de la caridad. El poema "La beneficencia" explicita la ventaja de mantener este orden, que consiste en que los ricos puedan hacer el bien: "Tu generoso espíritu / Todo el imán posee; / y hoy al brillar magnífico / Tu sol, mis vagos cánticos / A sus esencias místicas / En tí consagraré" (p. 110). En definitiva, el orden social existente permite que pobres y ricos alcancen los bienes celestiales, a través de la resignación y de la caridad, respectivamente. Los bienes terrenales derivados del celebrado progreso técnico, en cambio, son exclusivos para los ricos.

Una vez más, los poemas de Montes del Valle reflejan el imaginario dominante entre los intelectuales. Como recuerda López Cortés (2008a), los discursos de la época se centraban en avanzar hacia la "civilización" a través del progreso, la producción y la ciencia (importada), lo que solía combinarse con la religión católica, pero continuaban marginando a las clases subalternas, que incluían a indígenas, afrodescendientes, pobres, campesinos y mujeres (pp. 198-203). Montes del Valle, aunque perteneciera a uno de estos grupos subalternos (el de las mujeres) y se definiera como "pobre" (pertenecía, en realidad, a lo que hoy llamaríamos “clase media”), nunca buscó un cambio profundo en la estructura social de Colombia. Al fin de cuentas, este orden había sido inspirado por Dios.

De forma análoga, como avanzábamos anteriormente, la religión es un componente esencial en la visión de Montes del Valle, quien en todo momento enlaza ciertas ideas positivistas con la inspiración divina que propicia el progreso. El medio visible de dicho progreso, en todo caso, es el trabajo. Existen referencias explícitas a esta actividad en la práctica totalidad de los poemas que abordan la temática sociopolítica.Además, Montes del Valle (1883) dedica un largo poema exclusivamente "Al Trabajo”, que comienza con los versos "Hosanna en las alturas y en la tierra / A ti, ley redentora del trabajo, / Fuerza descubridora, ley divina"(p. 41). La poeta utiliza una palabra litúrgica ("Hosanna”) para vincular el trabajo con el plano celestial. 
El propio Dios se presenta como un trabajador, "que de la nada crea", semilla del ser humano que "como si fuera Dios / Elimina el vacío en las distancias, / Esclaviza la luz; rige, sojuzga / La ajena voluntad al magnetismo" (p. 42). Desde la perspectiva actual, puede parecernos pernicioso este imaginario de ilimitada dominación de la naturaleza (hoy lo asociaríamos a un neoliberalismo salvaje que pone en peligro el medio ambiente y las comunidades indígenas y campesinas), pero en la época en que escribe Montes del Valle supone una relativa novedad respecto al inmovilismo de la época colonial (con precedentes a finales del siglo xviII, como ya vimos). Recuerda Jaramillo Uribe (1964) que la segunda mitad del siglo XIX experimentó un cambio en el imaginario de la clase dominante, que ya no se avergonzaba de comerciar y de trabajar (pp. 167-168). En general, podemos afirmar que en este cambio se verifica el paso de una sociedad señorial a una ideología burguesa.

Ahora bien, ¿cómo podía vincularse esta nueva visión positiva del trabajo con la idea de Dios? Afirma López Cortés (2008b) que existieron dos visiones contrapuestas sobre el trabajo desde la perspectiva cristiana. Por un lado, el trabajo como castigo divino derivado del pecado original; por otro lado, el trabajo como actividad útil y digna (p. 68). Agrega Medá (1998, pp. 43-49) que la primera visión fue transformándose hasta generarse una asociación entre la creación divina y la humana; y, ya en el siglo xix, se conforma la idea de un Dios trabajador. Es en este contexto que debemos ubicar la ya citada oda "Al trabajo": "Tú no eres maldición de la existencia" (Montes del Valle, 1983, p. 46), "Paladín invencible del progreso, / Digna imágen de Dios sigue su obra” (p. 45). En esta idea del trabajo se unen los esfuerzos físicos e intelectuales, incluyendo el "altar del pensamiento" y "los secretos éxtasis del alma" (p. 46), lo que, en última instancia, supone una equiparación entre el obrero y el poeta. La conexión entre religión, trabajo y progreso también puede perfilarse en la propia vida de Montes del Valle, quien siguió el lineamiento propuesto por Acosta de Samper en el sentido de mantener un trabajo remunerado en el ámbito educativo.

Finalmente, nos referiremos al poema "A Antioquia", por suponer una perfecta articulación de los elementos anteriores: religión, trabajo, educación y progreso. Montes del Valle (1883) describe a los antioqueños como una "Raza privilegiada, raza altiva, / Emprendedora, atlética, indomable”: una caracterización que también 
encontramos en "El canto del antioqueño" de Epifanio Mejía, y que perdura hasta el día de hoy. Sin embargo, a diferencia del "himno" de Mejía, Montes del Valle (1883) critica el espíritu belicoso y ensalza el trabajo orientado al progreso: "Levanta de tu lecho fratricida / Legendario pais de la riqueza / Del genio, del honor, de la grandeza / Del trabajo industrial" (p. 15). A su vez, el progreso y el trabajo se asocian a la educación: "educa, inicia, ampara, desarrolla. // La noble inteligencia / Desata en los caudales de la ciencia” (p. 16), siempre bajo la mirada de Dios. La expresión “apóstol del progreso" (p. 16) resume a cabalidad el imaginario de nuestra poeta.

\section{Conclusiones}

En el presente artículo hemos intentado revaluar la olvidada figura de Agripina Montes del Valle, que resulta relevante no solamente para la historia de la poesía colombiana, sino también para la historia intelectual del país tanto por su contribución a las redes de mujeres intelectuales como por la elaboración de un imaginario que articula la religión y el progreso. En todos estos aspectos, el caso de Montes del Valle resulta problemático, lleno de contradicciones y tensiones que quizás debamos atribuir a las limitaciones de su tiempo.

En cuanto a su actuación como mujer en la ciudad letrada, es necesario resaltar que, junto a numerosos poemas de circunstancias claramente adscritos a lo que se esperaba de una delicada y doméstica "poetisa”, Montes del Valle revela sus logros en tres sentidos: la denuncia explícita de la desigualdad entre mujeres y hombres en cuanto a las posibilidades de dedicarse a la escritura; la tendencia democratizadora, al reivindicar su origen social lejano a la élite y al pretender que la escritura se convirtiera en un trabajo remunerado, y la práctica de una poesía de aliento épico y temáticas sociales que contrasta no solamente con las características atribuidas a las mujeres poetas, sino también con el sistemático olvido de la realidad circundante en la poesía colombiana escrita por hombres (con excepciones como la de Candelario Obeso).

En cuanto a las ideas sociales concretas de Montes del Valle, lo cierto es que responden al pensamiento más habitual entre los intelectuales colombianos de la época. En especial,1lama la atención la forma en que se articulaba el conservadurismo 
religioso y la idea de progreso, dos ámbitos que hoy en día suelen ser concebidos como contradictorios. Desde la perspectiva actual, se advierten graves descuidos en las imágenes sobre los grupos desfavorecidos: Montes del Valle exalta a los indígenas del pasado, pero relega y olvida por completo a las comunidades ancestrales de su presente; la poeta se declara "pobre" y tiende a una cierta democratización, pero en los poemas afirma que para el pobre solo debe haber resignación y caridad. Por otro lado, tanto el "progreso indefinido" como la dependencia europea resultan chocantes para nuestro pensamiento decolonial.

En otro orden de cosas, debemos distinguir entre el interés de la vida y de las ideas de Montes del Valle, y el disfrute estético que pueden originar sus poemas. Al igual que sucede con la práctica totalidad de poetas del siglo xIX colombiano, la poesía de Montes del Valle se basa en principios que ya no son los nuestros y difícilmente pueden ocupar la atención de un lector en el siglo xxi: en especial, la subordinación de un poema a un mensaje externo (sea ideológico, como el del progreso; sea doméstico, como la celebración de un cumpleaños), la ausencia de contención verbal y la repetición de estrategias retóricas ya gastadas, la exacerbación del sujeto lírico y el tono grandilocuente o lacrimógeno, etc. Por el contrario, el defecto que más le criticaban en su tiempo (las incorrecciones métricas y otro tipo de licencias técnicas), puede ser leído hoy en día como una exploración de nuevas posibilidades líricas, aunque no llegara a alcanzar la libertad de la poesía moderna.

En definitiva, consideramos necesaria una edición crítica de la poeta, así como nuevos estudios que puedan comprender la totalidad de su obra, que solo hemos tratado de manera parcial. Investigaciones futuras podrían ampliar las dos problemáticas que aquí hemos abordado desde el análisis de Montes del Valle: los imaginarios de progreso en la literatura colombiana y las redes intelectuales de mujeres en el siglo xıx. Este último aspecto, que ha despertado el interés de la crítica en las últimas décadas, puede arrojarnos resultados de mucho valor, como la posibilidad de que los casos de Acosta de Samper y de Montes del Valle no fueran excepcionales, sino que la segunda mitad del siglo xix hubiera alumbrado a las primeras generaciones feministas de nuestro país. 


\section{Referencias bibliográficas}

Alzate, C. (2004). Mujeres, nación y escritura: no hablar, ni de qué hablar. En S. Castro-Gómez (Ed.). Pensar en el siglo XIX. Cultura, biopolitica y modernidad en Colombia (pp. 273-285). Pittsburgh: Instituto Internacional de Literatura Iberoamericana.

Arango Ferrer, J. (1965). Raiz y desarrollo de la literatura colombiana. Bogotá: Lerner.

Bermúdez, S. (1993). El "bello sexo" y la familia durante el siglo xIx en Colombia. Revisión de publicaciones sobre el tema. Historia crítica, (8), pp. 34-51.

Gómez Restrepo, A. (1952). La literatura colombiana. Bogotá: Editorial A.B.C.

Jaramillo Uribe, J. (1964). El pensamiento colombiano en el siglo XIX. Bogotá: Temis.

López Cortés, Ó. A. (2008a). El discurso del trabajo durante el siglo xıx. En F. S. Benavides (Ed). La constitución de identidades subalternizadas en el discurso jurídico y literario colombiano en el siglo XIX (pp. 163-217). Bogotá: Universidad Nacional de Colombia.

López Cortés, Ó. A. (2008b). Trabajo: Ni Castigo Ni Bendición de Dios. Porik An. (13), pp. 59-92.

Lux, M. (2015). Mujeres patriotas y realistas entre dos órdenes. Discursos, estrategias y tácticas en la guerra, la politica y el comercio (Nueva Granada, 1970-1830). Bogotá: Universidad de los Andes.

Medá, D. (1998). El trabajo. Un valor en peligro de extinción. Barcelona: Gedisa.

Montes del Valle, A. (1868). Proyectos de literatura. El Oasis. Periódico literario, I, IV (40), pp. 312-316.

Montes del Valle,A. (1872). Ami señora doña Pia Rigan. El Mosaico. Periódico de la juventud,II (27), p. 212.

Montes del Valle, A. (1879). La azucena y la rosa. La Mujer. Revista quincenal, (19), p. 159.

Montes del Valle, A. (1883). Poesías. Bogotá: Imprenta Zalamea.

Montes del Valle, A. (1892). "Carta”. Revista Gris. Publicación mensual, 2, pp. 35-36.

Ortega Torres, J. J. (1934). Historia de la literatura colombiana. Bogotá: Escuela Tipográfica Salesiana.

Pombo, R. (1883). Las sacerdotisas. En Montes del Valle, A. (1883). Poesías. Bogotá: Imprenta Zalamea, pp. III-LII.

Valera, J. (1958). Cartas americanas. En Obras completas (Vol. III) (pp. 211-312). Madrid: Aguilar. 